\title{
The Burnout Syndrome-A Synopsis of Time and Body Experience of Patients Suffering from Burnout
}

\section{David Duncan}

Movement and Sports Pedagogy Research Group, Institute of Sports Science, University of Graz, Graz, Austria

\begin{abstract}
Background: Is the burnout syndrome the widest spread disease in today's modern Western society? It is, at least if you valuate its popularity by the constant media attention it catches. This article aims to combine two previous studies on body- and time-experience of Burnout-patients. After describing the time-experience of the individual Burnout-types, this article will also confront the two, to deepen the understanding for the different approaches towards time.

Methods: The answers of 48 guided interviews were analyzed using the qualitative content analysis by Mayring and later assigned to the results of an earlier quantitative research.

Results: Burnout patients can be divided into two groups. This theory is not only supported by the quantitative results of the analysis of the KBMTs, which showed significant differences between the two groups, but also numerous items of the qualitative analysis of the guided interviews strengthen this theory.

Conclusion: The two types of Burnout-patient share the fait, that their time-experience is strongly attached to external rhythms. However, one type seems to take on more of a "suffering" role, as he/she would have the time resources to support their own well-being, while the other type seems to be solely concentrated on his/her job and therefore puts every possible minute of their day into it. Both types lose their individual time-rhythm and also the feeling for their own body, but do so in very distinct ways.
\end{abstract}

\section{Publication History:}

Received: December 10, 2019

Accepted: January 02, 2020

Published: January 04, 2020

\section{Keywords:}

Burnout, Burnout-syndrome, Time-experience, Bodyexperience, Body image

\section{Introduction}

Is the burnout syndrome the widest spread disease in today's modern Western society? It is, at least if you valuate its popularity by the constant media attention it catches. Two decades ago Maslach [1] published her first book on Burnout and since then hundreds and hundreds of researches, articles and books have been published on the topic. Nowadays it seems common knowledge, that the Burnout syndrome is not only a "helpers- and caretakers"-disease, as it was first coined in the 1970s by Freudenberger, who used the term to describe the consequences of severe stress and high ideals experienced by people working in "helping" professions. As the body of work on this syndrome has grown, more and more researches have shown that this illness is not only found in helpers-jobs, such as doctors and nurses, as Freudenberger originally described them, but can be found in any job field, such as managers, teachers and politicians, but also with housekeepers and homemakers. Also the work is not always a "classical" job, but also the voluntary efforts to take care of family members at home can lead to burnout. At the end of the day, everyone can end up exhausted, listless and unable to cope, and once those symptoms turn into a chronical state of exhaustion, one can describe it as a Burnout.

However, it needs to be addressed that there seems to be a big discrepancy between published opinion and specific knowledge. As the burnout syndrome tends to be mixed up with work-related stress in the media, everybody thinks of him- or herself as a specialist. This is quite understandable, as almost everyone has experienced negative emotions inflicted by work-related stress over his or her working career. The burnout syndrome has been the subject of numerous researches, carried out by psychologists and sociologists over the last decades, helping to analyze, identify and classify the spreading illness. The main problem for scientific research is caused by the simple fact, that there is no generally accepted definition of burnout, as the separation from other illnesses and disorders is difficult.
This article intends to bring together two studies, namely a study about time-experience of burnout patients and a second study, analyzing the body-experience of burnout patients, to round off the picture of burnout patients described in earlier studies, which should lead to a deeper understanding of the importance of time- and bodyexperience found in this illness.

Burnout is considered to have a wide range of symptoms, such as depression, moral conflicts and senselessness. Additionally most longitudinal researches substantiate the thesis that chronic stressors at work and burnout are reciprocally related over time [2-4]. At the core of burnout lays the depletion of individual energetic resources, as represented by feelings of physical fatigue, emotional exhaustion, cognitive weariness, alienation from family and friends and reduced performance $[5,6]$. This is caused by the inability to find and use spare time to recharge, which is generated by the immanent synchronization with organizational rhythms of external occasions, rather than to follow natural intent of one's personal needs.

Additionally to the aforementioned psychological symptoms, patients who suffer from "burnout" also suffer from physical symptoms, such as cardiovascular dysfunction, indigestion, sleep disorder and disturbance of the hormone-cycle. These ailments seem to be connected to a disturbance of the psychosocial rhythms of the patients, put in simple words - the time-experience of these patients seems to be disturbed. Duncan [7] looks deeper into the factor "time-experience" and describes the subjective time-experience of burnout patients.

${ }^{\overline{ }}$ Corresponding Author: Dr. David Duncan, Movement and Sports Pedagogy Research Group Institute of Sports Science, University of Graz, Mozartgasse 14 A-8010 Graz, Austria; E-mail: david.duncan@gmx.at

Citation: Duncan D (2020) The Burnout Syndrome-A Synopsis of Time and Body Experience of Patients Suffering from Burnout. Int J Phys Ther Rehab 6: 161. doi: https://doi.org/10.15344/2455-7498/2020/161

Copyright: (C) 2020 Duncan. This is an open-access article distributed under the terms of the Creative Commons Attribution License, which permits unrestricted use, distribution, and reproduction in any medium, provided the original author and source are credited. 
The aforementioned studies show that the factor "time" plays an integral part in the understanding of this illness. However, fewer studies have looked into the importance of the factor "bodyexperience". Litzke and Schuh [8] argue, that burnout-patients do not "feel" their bodies like healthy people. Furthermore, Duncan [9] adds how the body of burnout-patients is represented in their minds and what kind of differences exist compared to the body-experience of healthy people. Additionally Duncan describes two major types of Burnout-patients and how they differ in level of differentiation of and satisfaction with their bodies.

This article follows up on the research of body-experience of Burnout patients and intends to describe the self-reflected timeexperiences of these participants, using a qualitative analysis to deepen the understanding of earlier, quantitative results. Through this, earlier found types of burnout patients will be described in more detail and underlying patterns of behaviors concerning the handling of time will be pointed out. Additionally it will be shown, how the body - experience of burnout patients is represented in their selfreflected time-experience.

\section{Object of Research}

Before looking into the details of this study, the results and objectives of the underlying studies have to be briefly summarized and explained. It is imperative to understand the concept of bodyexperience and time-experience before bringing the two studies together.

\section{Body-experience and body image}

As the area of body-experience and body image is a wide field [1012], it has to be clarified that two sub-categories are of interest for the underlying study.

Firstly the area of body satisfaction, which Schilder [10] describes as a "picture of our own body which we form in our mind, that is to say the way in which the body appears to ourselves (...), the picture of our own body which we form in our mind, that is to say the way in which the body appears to ourselves." Müller [11] adds that this phenomenon is a psychological experience, focusing on feelings and attitudes towards one's own body.

Secondly, the underlying study focuses on the area of bodyexperience, more precisely on the subarea of body-differentiation. Duncan [13] argues that it is not only important whether the patients have a positive or negative attitude towards their bodies, but also how differentiated they are able to "feel" or "reflect on" their body. It is argued in specialist literature that patients who suffer from psychological disturbances experience their body less differentiated than healthy people [14]. Furthermore, it can be said, that people who do not "feel" their own body and their needs are highly endangered of suffering from burnout, as they neglect the symptoms and warning signs their body sends out $[15,16]$. To "feel" one's body, a person has to be able to differentiate his or her body. Müller [11] states, that a high level of differentiation leads to a stable integration of the body image into one's mind and therefore also leads to a stable concept of oneself, which is vital to avoid Burnout and other psychological malfunctions.

In the first results of underlying study, which solely focused on the body-experience, Duncan [13] argued that:
Burnout patients, especially in the early stages of therapy, seem not to be conscious of their bodies. Either they experience it as one whole, without being able to differentiate between body parts, or they experience only disconnected areas of pain. Either way, the level of differentiation is very low. The two types, who had not experienced a lot of therapy, due to the fact that their hospitalization had not been long before the testing, show a severe difference in level of satisfaction (Figure 1 \& Figure 2); however over the course of the therapy they experience, these levels approach the levels of the control group [13].
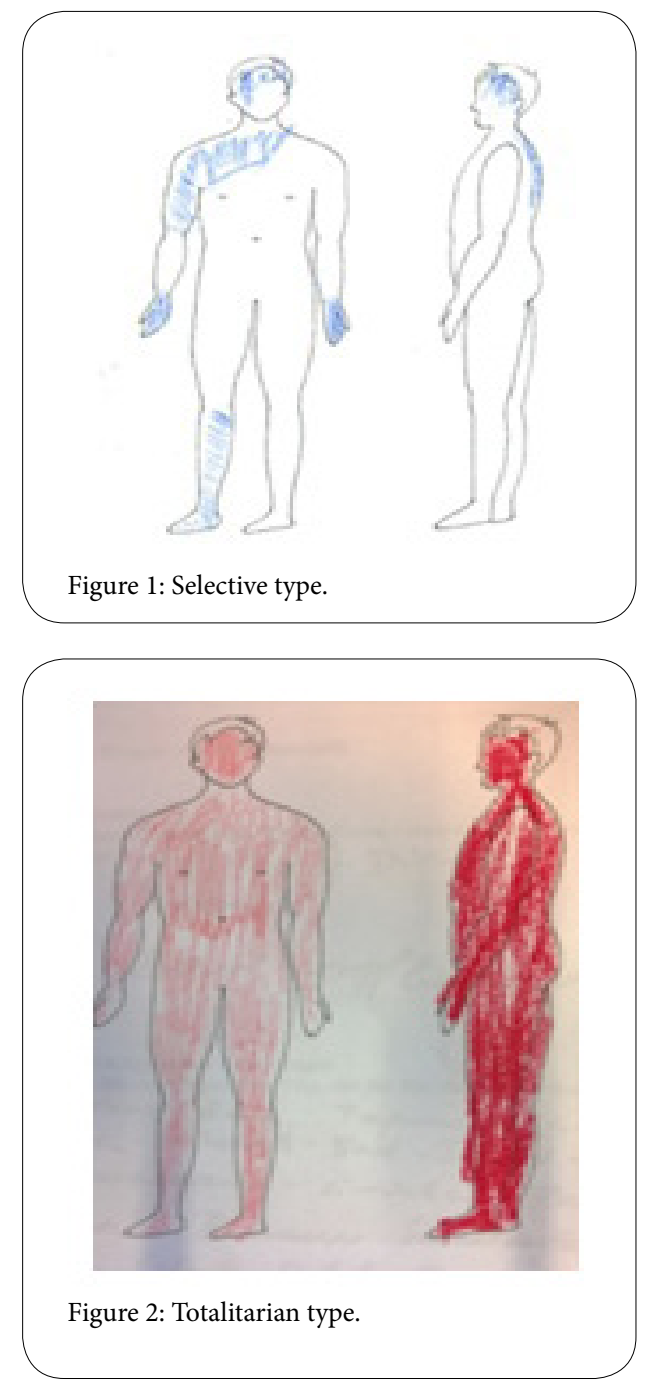

\section{Time-experience}

In his works, Duncan [7] describes in detail, how the Burnout - syndrome and the factor time are closely tied together. From increasing walking speeds in cities $[17,18]$ to job insecurity because of time flexibility [17], time obviously plays a central role in the building pressure on workers and employees. Furthermore time pressure in the working environment is increasing rapidly, Blasche [17] quotes the European Working Conditions Survey, which states, that the percentage of workers, who work to tight deadlines at least a quarter of their working time has increased constantly over the past 20 years in Europe. In 2010 more than $60 \%$ of all employees had to face the immense pressure of working towards deadlines at least a quarter of their working time, in 1991 less than 50\% stated the same. 
Besides the mentioned statistics, also the symptoms of Burnout syndrome point into the same direction. As mentioned above, the main symptoms of Burnout are described as "emotional exhaustion", "alienation from family and friends" and "reduced performance", but in latest studies [7] a further keystone has been established - the factor "time"."Patients, who suffer from "burnout" are reportedly afflicted by sleep disturbance and cardiac dysrhythmia in many cases. These ailments seem to be connected to a disturbance of the "psychosocial rhythms" of the patients, put in simple words - the "time-experience" of these patients seems to be disturbed [9].Apparently the timeexperience of the work environment has carried over to the individual time-experience.

This work intends to bring two studies together, namely a study about time-experience of burnout-patients and one which was focused on the body-experience of the same patients. In the course of this article, the findings of the study on body-experience [13] will be taken up and furthermore will look into the self-reflected time-experience of the same patients. These steps are taken to deepen the understanding of earlier quantitative results by using a qualitative approach. Hereby the Burnout-syndrome will be examined from a subjective perspective, outlining the fundamental handling of time and the subjective bodyexperience. In a further step the underlying qualitative study [7] will be complemented by a qualitative-quantitative study [13], which was solely focused on the body image.

The earlier mentioned study on body-experience and bodydifferentiation [13] introduced two major types of burnout patients, namely the "selective" and the "totalitarian" type - to add to these findings, this article intends to bring together the documented bodyexperience [13] and the obtained data on time-experience of those interviewees to show how body-experience is mirrored in timeexperience.

As the two types are essential for this work, the result of Duncan's findings [9] will be summarized in the following sub-chapter.

\section{Materials \& Method}

\section{Study on time-experience [7]}

To investigate the topic of "Time - Experience", or, more specifically, the aspect of conscious regulation and the conscious subjective experience of time, a guided interview [19] was carried out.

This interview, which contains 26 questions, centers on four main areas:

1. General questions about the topic "Time"

2. Characteristic features of "experiencing" and "handling" time

3. Reasons and matters for "experiencing" and "handling" time

4. Coping skills for the handling of "Time" as a limited resource

After completing the 45 minute - interviews, they were transcribed and later analyzed, using the qualitative content analysis by Mayring.

\section{Study on body-experience [13]}

To explore the conception of and satisfaction with their own body a Colour-a-Person-Dissatisfaction-Test (Körperbildmaltest) was carried out. This tool was used to analyze how satisfied they are with their body and also how differentiated Burnout-patients experience their own body.
The Colour-a-Person-Dissatisfaction-Test (Körperbildmaltest) was designed by Günter [16] for the testing of children, later adapted for adults by Geiger. This test holds the advantage, according to Günter, that the body experience is portrayed visually and graphically, in contrast to most questionnaires and interviews, which have to rely on the ability of the interviewee to depict their feelings towards their body verbally, which is often a challenge. Furthermore, this test offers the opportunity to not only investigate the patients's satisfaction with their body, but also analyze their ability to differentiate their body.

\section{Setting}

83 Colour-a-Person-Dissatisfaction-Tests (=CaPDTs) (Körperbildmaltest) and 47 guided interviews were carried out. 47 CaPDTs and all the interviews were conducted with patients, who were hospitalized at the same hospital (AMEOS Klinikum Bad Aussee/ Austria) with the primary diagnosis "depression" with an additional diagnosis "burnout" for at least 1, max. 10 weeks. The group consisted of 24 female and 23 male patients, aged between 38 and 76. All patients were assigned by the chief resident and the participation was voluntary.

These testings were flanked by 36 CaPDTs, which were carried out with a control group, all participants work for the same company and were diagnosed as "healthy" by the company's occupational physician. The control group consisted of 22 women and 14 men, aged between 18 and 55 . The participation was voluntary.

\section{The synopsis of body-experience and time-experience}

As the mentioned studies of time-experience and body-experience were conducted with the same patients, it was an obvious choice to bring together the findings of the two. To perform this synopsis the following steps were taken.

Step 1: The findings of the study on body-experience [13] were taken as starting material.

Step 2: The interviews of the patients, who formed the intersecting set of the totalitarian and selective type were picked out assigned to the two categories.

Step 3: After assigning the patients to their respective groups, the transcripts of the interviews of the members of the various types were analyzed and categorized, using the qualitative content analysis of Mayring.

Step 4: The categorized answers of the two types are being separately portrayed.

\section{Results}

To deepen the understanding of the different types of Burnoutpatients, the two kinds are characterized by citing answers of the interviews in detail. By doing so this chapter aims to develop an understanding for the time-experience of the two, earlier found types of Burnout-patients [13].

\section{The selective type}

Stereotypically speaking, members of this type often have to take care of relatives / in-laws at home, so their "job" does not end when they come home, but they have the feeling of being on duty 24 hours a day. When asked about on which areas of their lives they focus their drive, many members of the selective type stated, that they felt 
completely listless, or that they were only in "survival mode", which indicates that all kinds of personal interests are being reduced to the absolute minimum, just focusing on making it through the day.

Members of this group seem extremely exhausted. Time is mostly noticed when it centers around work and stress, and even when there is, or rather would be, time at hand, members of this type often lack the drive to put it to good use. They seem to have the feeling that the workloads never stop, as many of them not only have to work their regular job, but are also concerned with housekeeping. Even when there is enough time for activities of personal interest, they just cannot use it, as they are too fatigued. Moreover, they only feel parts of their body, which they encounter as dissatisfying and often as painful areas. Their body-experience can be described as a collective of snapshots, which show painful areas across their body.

To go into more detail, when members of this group were asked when they notice time, some answers included the following statements: "It is difficult to keep track of time, even which day or date it is. I am unable to estimate the hour of the day or how long things last for - even how long it has been since something has happened" (patient s1), "I have to hurry home, because my mother-in-law is there. That is very stressful. I always hope that nothing has happened to her. Even when I am shopping I have to hurry. And I still have a bad conscious." (patient e2) and "I notice time when I have appointments - I meet deadlines, which is very important to me ... but I have to say that it stresses me out." (patient q1) "My time was strictly used for appointments - and there was never enough time. Enjoying time was unthinkable" (patient $y 1)$. It can be summed up, that the patients experience time mostly as something negative. To notice time often goes hand in hand with the lack of the same or the need to meet certain deadlines.

When asked what they would do with 3 hours of spare time on their hands, the patients of this type answered as follows: "I'd drive home - there is always work waiting" (patient i2), "That would have never happened" (patient q1), "I would have never treated myself to that - I would have had a bad conscious" (patient s1), "I cannot answer this question - I do not know a situation like this". (patient $\mathrm{z} 1$ ), "I'd drive into the mountains and go hiking" (patient $\mathrm{y} 1$ ), "I would meet up with friends" (patient h1). With these answers, the patients show a variety of motivations to use the time in hand, an interesting fact however is, that only patients of this type mention the fact, that they would use the time to catch up with the housekeeping and also far more members of this group state, that they are lacking the drive to put the time at hand to good use for themselves.

The separation of work and recreation seems mostly unthinkable for both types, however, a trait that stands out with members of the selective type is the fact, that almost half of the patients have the feeling that they have sufficient time for activities of personal interest, but more than half of these patients furthermore state, that they feel unable to use the time actively. They state for example "I'd have the time, I just don't take it" (patient i2), "I'd have it - well, I do have it. I just let all the things which are important to me fall along the wayside. I just do not have the drive to do anything." (patient q2) "I do have the time, but I cannot translate it into action. I just cannot put it to use. (...) I just can't." (patient q1).

A further item of interest focuses on the drive of the interviewees. The unique feature of members of the selective type is that half of the interviewed patients stated, that their sole focus of drive is either nonexistent or that they exclusively try to survive. Which sounds very extreme in the first moment, but if one considers how the patients experience their bodies and also how they only focus on the past or the future, it seems as they just cannot bare the present and their sole thought is to somehow get through this phase of their lives. Patient v2 states "I just want to get better. I want to get rid of the anxiety states and just be able to go out and have a coffee..." while patient r1 speaks about sole survival "I get back on my feet, no matter how difficult it is. I had cancer 5 or 6 years ago. But I am a fighter, that's what everyone says about me". Patient j1 describes his listlessness as follows "I don't know where my focus lies. I walk up three flights of stairs and feel like I have no drive left in me" and patient q1 adds, that his sister is his drive, as he has given up on himself altogether.

As shown in earlier studies [7], the focus of Burnout patients is strongly focused on either the past or the future. When looking specifically at the selective type, the past seems to play the biggest role in their lives. Patient $\mathrm{f} 2$ states "the past plays the biggest role, as that is the state I want to get back to". Patient e2 adds "the past is where I lay my focus - I had a really good childhood". Even more detail is provided by patient $\mathrm{z} 1$, who states the following "Approximately between 11997 and 1999 was my favorite time span. Before that I had some good times in 1995 where I felt quite well." These snapshots of their time-experience are also reflected in their body-experience, as these patients do not experience their lives (including their bodies) as one whole, but as tiny glimpses.

The same pattern can be found when looking at the item whether and how the profession of the patients influenced the experience and the handling of time. The selective type showed a wide range of answers - again many different snapshots of experiences, as also seen in their body-experience, while the totalitarian type was very "one-dimensional". The answers to "How the job influenced their time-experience?" spread from "everything is job centered" (patients $\mathrm{h} 1, \mathrm{j} 1, \mathrm{f} 2, \mathrm{i} 2$ ), over "In my job time was passing really quickly. It was too much. I didn't even have lunch" (patient s1), to "being on time" (Patient q1) and "I felt constantly driven" (patient r1).

The final item of interest was the question whether the patients had the feeling that they were, in fact, feeling their body. Here it has to be mentioned that the difference of the two groups seems odd. The members of the selective group mentioned mostly, that they did not feel their own body. Nevertheless they highlighted at least certain areas of their body, which is an indicator, that in fact they were feeling their body. The totalitarian type did not highlight areas, but colored the entire schema of the body, which leads to the conclusion, that the members of this group did in fact not perceive their body.

\section{The totalitarian type}

This type of patient is your prototypical "doer" - someone who makes things work in his job, is available 24 hours a day and defines him/herself through success in their work life. One patient stated, that he would go into work even on holidays, as he was sure that nothing would work if it was not for him (patient e1).

Members of this type notice time in a multitude of ways - they seem very reflected on what they do with their time, which apparently gives them a feeling of control, a trait which seems to be desirable for this type of patients, as he/she strives for control over every aspect of their life. Patient $\mathrm{d} 1$ explains, that he notices time when it is running out but in general that time management had never been a factor for him. The same seems to be true for patient $\mathrm{k} 2$, as he/she notices 
Citation: Duncan D (2020) The Burnout Syndrome-A Synopsis of Time and Body Experience of Patients Suffering from Burnout. Int J Phys Ther Rehab 6: 161. doi: https://doi.org/10.15344/2455-7498/2020/161

Page 5 of 9

time when there are deadlines to be met. Appointments and deadlines seem to play an important role for this type of patient. Patient p2 states, that his/her entire day consists of appointments and that he/ she reflects on time solely by these. In general it can be said, that this type of patient has to follow a tight schedule, which he/she finds very stressful. Positive connotations toward time stand upright as long as the deadlines can be met, but step by step the stress gets to the patients.

When asked about what they would do with unexpected free time, the patients of this group mentioned that they would either work or do something for themselves, such as spending time in nature or in a spa. "I would sit in my convertible and take off to a nice spa-resort and use the time at hands for myself - all the others can go and get stuffed" (patient c1), "I'd set off into the mountains, the only hobby I have left" (patient $\mathrm{m} 1$ ), but not all patients would act as wisely. For example patient $\mathrm{d} 1$ mentioned that he would find and do work, as taking time off had not happened in the past 29 years A lack of drive was not mentioned in this group, as again they try to show that even in hospital, they are aware of their "flaws" and pretend to know, what they need. Another interesting answer, which was missing with this type, was that none of the patients mentioned that they would do housekeeping in the unexpected free time, an answer which occurred quite often with the selective type.

The totalitarian type is very clear when it comes to work and recreational time - when asked about separation of work and free time, all but one answered that the separation was not existent, just as time at hand for activities of personal interest. Patient $\mathrm{d} 1$ mentioned that his/her mind never left the office, as he was unable to keep his/her thoughts off work. Patient $\mathrm{x} 1$ adds, that negative experiences in the working environment carry over to the free time. "In the last few years I did not have time for personal interests - the last 10 years" states patient $\mathrm{x} 2$. The same is added by patient $\mathrm{c} 1$, who says that he/she had not found time for personal interests in the past 4 years.

The patients listed that they focused their drive on labor and the fulfillment of expectations - personal interests like family, hobbies or even survival played a minor role. Patient $\mathrm{d} 1$ explains his situation as follows "Even though the company never asked for it, I put all my drive into my job. This was not the company's fault, but my own." Patients f1 and $\mathrm{m} 1$ answered where they lay their focus on with just one word "job". And patient k2 adds, that he/she put way too much energy and focus into his/her job, and even when this was done, the rest of his/ her energy was put into the housekeeping. Focus on personal interests and social contacts was almost nonexistent.

Asked about the time-periods which were of the biggest importance to them, the answers were very balanced. However, an answer that was very clear, was the one about how the profession influenced the handling of time - all but one member stated, that the job was the only center of their lives. The odd one out only answered, that his/her job was a plain burden.

The aforementioned stereotype of having complete control is also mirrored in the representation of the body. The patients have a very positive feeling towards it, but this seems very superficial. In the minds of the totalitarian type, a body has to do its job, namely function, and as long this is the case, they are satisfied. When it comes to differentiation, another indicator for a healthy relationship with one's body, the patients completely lack this ability. The feel their body as "one unity" rather than trying to listen to the body, telling them that they were in the process of suffering more and more from fatigue and sleeplessness.

\section{Conclusion - Comparing the Types}

To conclude this article, the types will be contrasted, to show the areas of difference and also similarities. To distinguish the two groups even more, the categories found in the qualitative analysis will be portrayed through the juxtaposition of the two different types.

To start of the interview, the patients were asked in which moments they notice time, they pointed out that time mostly strikes their attention when external occasions, such as labor or stress in general appear, rather than feeling the personal need for time. Some of the patients experienced time as something neutral or said, that they lack the ability to experience time altogether. The selective type (Figure 3) does not vary a lot in his/her answers - Labor, stress and even watching TV make them notice time, while some answered that during his/ her vacation time would strike their mind. Others pointed out that could never notice time, that it was undefinable or just something neutral, that happened all the time. The totalitarian type (Figure 4) shows a wide repertoire of answers, ranging from labor, service above self and appointments to the negative description of time being only noticeable when stress occurred, or even that it was described as strain or plainly as something negative. Only two patients mentioned that they consciously experienced time when performing their hobby. One person added that they noticed time when thinking about the future and past, but described this feeling as neutral. This does not surprise, as one of his/her traits is, that he/she strives to be in "total control" and seems very reflected on the many things he/she is doing with their time.

Another item of interest was the questions, what the patients would do with unexpected free-time at their hands. They were asked what they would do, if they suddenly had 30 minutes, 3 hours and at last 3 days to their personal disposal in the middle of a working day / week. What both types had in common was that for a lot of the interviewees, the thought of having 3 hours of spare time was unthinkable and that they had no idea what they would or could do with the time. However, what was interesting to see, was that when asked about what they would do with three days of spare time, that hardly any members of the selective type group (Figure 5) stated that they would use the time to cater personal needs, such as spending time outdoors or doing a short trip to a spa, but rather still use the time to do (domestic) work or simply lacked the inner drive to do anything. The totalitarian type (Figure 6) on the other hand shows a still existing need to also cater personal needs. Furthermore it shows, that only the selective type thinks about housekeeping, which apparently is not a part of the totalitarian type's mindset.

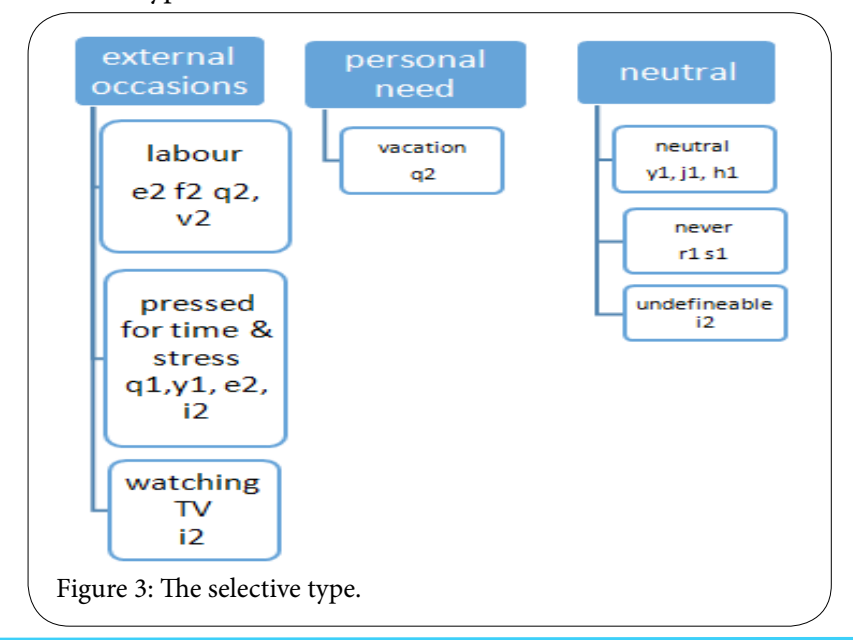

Int J Phys Ther Rehab

ISSN: 2455-7498

IJPTR, an open access journal Volume 6. 2020. 161 
Citation: Duncan D (2020) The Burnout Syndrome-A Synopsis of Time and Body Experience of Patients Suffering from Burnout. Int J Phys Ther Rehab 6: 161.
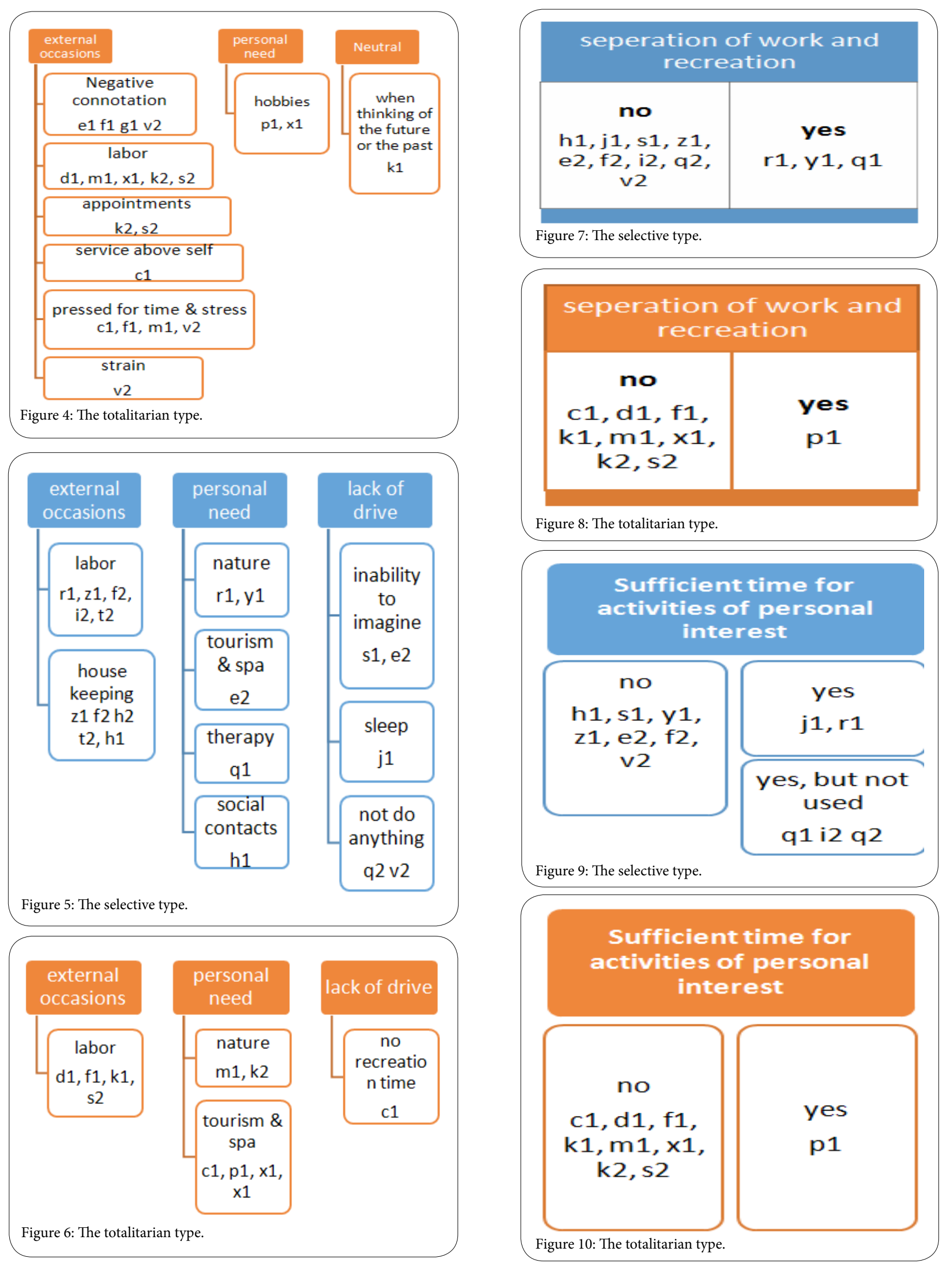

Int J Phys Ther Rehab 
Citation: Duncan D (2020) The Burnout Syndrome-A Synopsis of Time and Body Experience of Patients Suffering from Burnout. Int J Phys Ther Rehab 6: 161. doi: https://doi.org/10.15344/2455-7498/2020/161

Page 7 of 9

A further item of the interview was the aspect of work-life balance and the time- and spatial separation of work and recreation. Although both types clearly state that they are not able to spare work and recreation time (Figure 7 \& Figure 8) and furthermore do not have the sufficient time at hand for things of personal interest, there still seems to be a difference between the two types. More members of the selective type (Figure 9) seem to have time at hand for personal interest, however they seem to lack the drive to put it to use, whereas the members of the totalitarian type (Figure 10) simply feel that they do not have the time at hand.

Another element of interest focuses on the drive of the interviewees. They were asked on which areas of life the lay their focus and drive. Again the difference between the two types is significant. The totalitarian type (Figure 12) focus his/her drive mainly on external occasions, such as work, whereas many of the members of the selective type (Figure 11) describe themselves as listless or solely focus on surviving.

When asked to reflect on their handling of time, two items stood out. On the one hand, the patients were asked which period of time the past, the present or the future had the biggest importance for them. In past publications [13] Duncan argued, that patients suffering from Burnout were not able to live in the present, as they were too past- or future oriented, which denied them to enjoy the present and therefore prevented them relax and recharge. Looking into detail, there seems to be difference between the two types - the selective type (Figure 13) is stronger oriented towards the past, whereas the totalitarian type (Figure 14) does not seem to have a preference. Quotes by the patients of the selective type underline this finding, as they stress the importance of their past and how it is their goal to restore the days when they were feeling healthy.

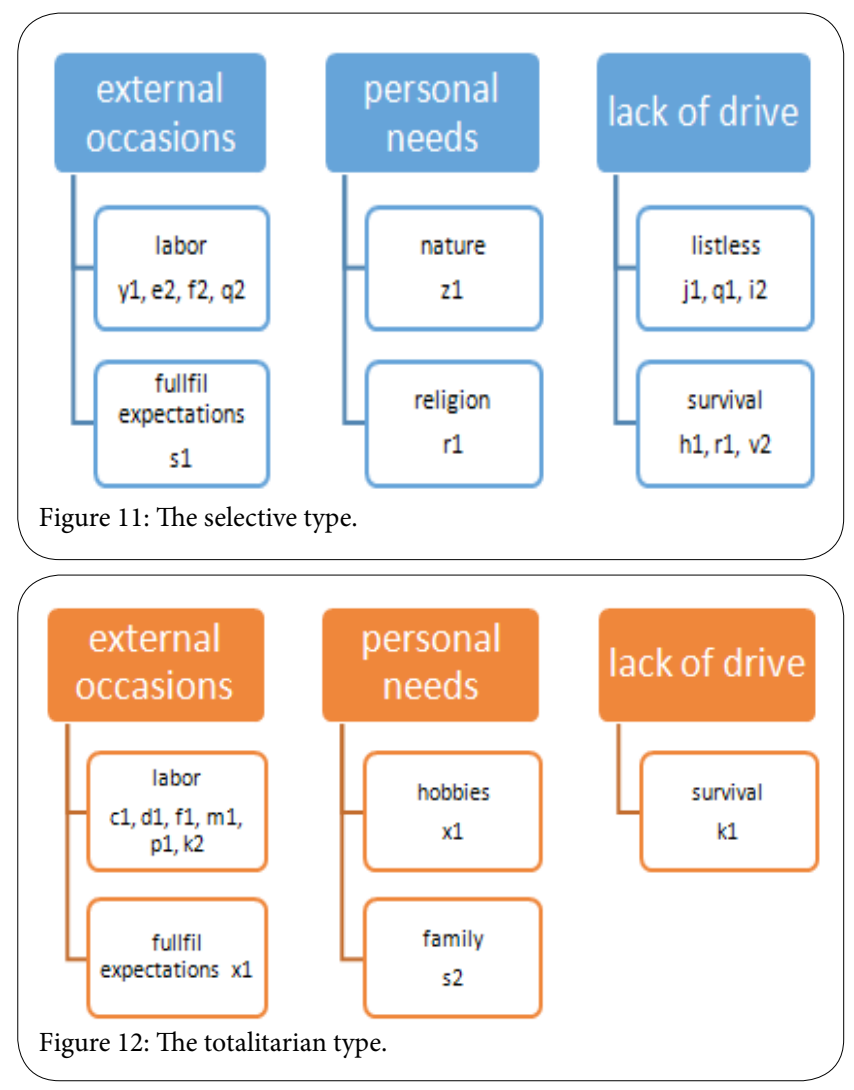

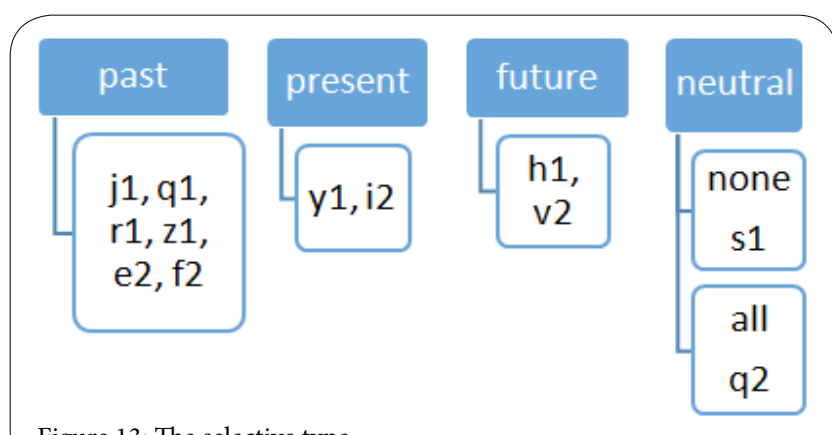

Figure 13: The selective type.

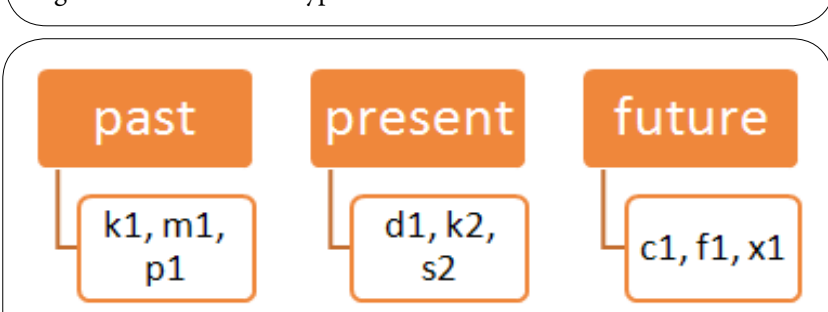

Figure 14: The totalitarian type.

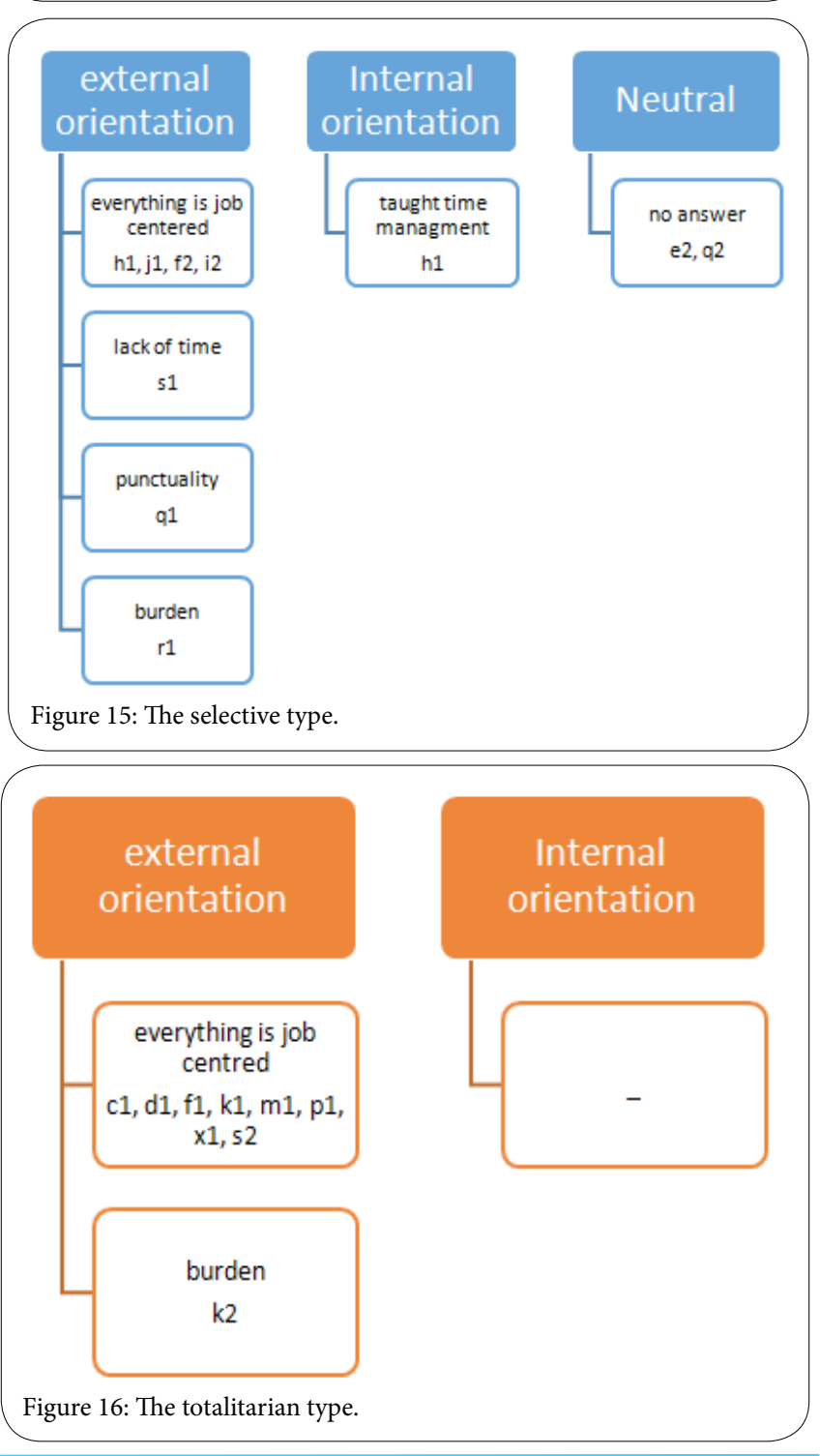

Int J Phys Ther Rehab

ISSN: 2455-7498

IJPTR, an open access journal Volume 6. 2020. 161 
Citation: Duncan D (2020) The Burnout Syndrome-A Synopsis of Time and Body Experience of Patients Suffering from Burnout. Int J Phys Ther Rehab 6: 161. doi: https://doi.org/10.15344/2455-7498/2020/161

Page 8 of 9

The second feature of interest was the question, how the profession of the interviewees influenced the experience and the handling of time of the patients. Again the difference between the two types was striking. The selective type (Figure 15) showed a wide variety of answers, circling around different time-related issues, such as punctuality, lack of time, time-pressure and structure forced onto the patient and also mentioning, that because of the job, the patient learned how to manage time effectively. On the other hand, the totalitarian type (Figure 16) solely stated that their complete time experience was only centered around their job. One patient mentioned that his/her profession was a burden.

The last component intends to show, how the KBMTs not only defined the two types by using level of body satisfaction and differentiation, but also are reflected in the interviews themselves. The patients were asked about personal needs - one item in particular was the question whether the patients had the feeling that they were feeling their own body. The selective type mostly answered this question with "no" (Figure 17), whereas most members of the totalitarian group stated, that they were in fact feeling their body (Figure 18).

To sum up the findings, it can be said, that Burnout patients can be divided into two groups. This theory is not only supported by the results of the analysis of the KBMTs, which showed significant differences between the two groups, but also numerous items of the qualitative analysis of the guided interviews strengthen this theory. Naturally a lot of the answers of the guided interview show parallels, as both types suffer from the same disorder, however it is possible to outline sub-categories of Burnout patients.

The members of these two sub-categories show a very distinct way of handling time and therefore it would be of great help to look deeper into this problematic field. One type of patients, namely the totalitarian type, is trying to stay in absolute control over "his" or "her" time and is being driven by his / her job. Even in hospital he / she is trying to portray themselves of having everything under control. It is obvious that the ability to separate work and free time has been lost a long time
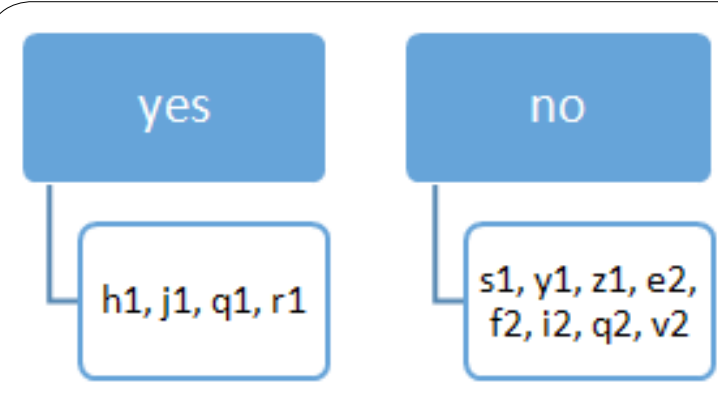

Figure 17: The selective type.

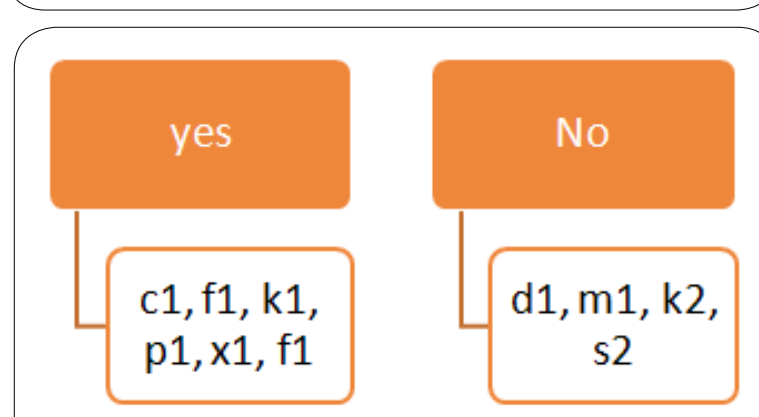

Figure 18: The totalitarian type. ago. The members experience their body as one "whole" - a machine that has to fulfill its cause, namely get them through the day. As long as the body is doing its job, the totalitarian type is very satisfied with it and does not seem to have negative feelings towards it - these only appear when they experience pain.

The selective type seems to be not as stressed for time as the totalitarian type, but seems to have lost his/her drive to do things for themselves. His/her drive is used to get through the day, in some cases to take care of their in-laws. The members of this group seem to be very past-oriented, as they wish to get back to the "good old days". Their experience of their bodies is very negative, as they only seem to feel their bodies once they experience pain. Other than that they appear to have lost the feeling for their bodies.

In future studies it would be of great interest to analyze whether the two types would produce different outcomes when being treated with "bodily" therapy, such as dance therapy. The findings outline archetypes of how patients experience their bodies and how they reflect on the issue "time" - a next step should be to introduce these findings in the therapy of burnout patients.

\section{Competing Interests}

The author declare that there is no competing interests regarding the publication of this article.

\section{References}

1. Maslach C, Jackson S (1982) The measurement of experienced bumout. J Occup Behav 2: 99-113

2. De Jong ED, Watson R, Pollack JB (2001) Reducing bloat and promoting diversity using multi-objective methods. In Spector, L. et al., editors, Proceedings of the Genetic and Evolutionary Computation Conference, San Francisco, CA. Morgan Kaufmann.

3. De Lange AH, Taris TW, Kompier MA, Houtman IL, Bongers PM, et al. (2004) The relationships between work characteristics and mental health: Examining normal, reversed and reciprocal relationships in a 4-wave study. Amsterdam: Taylor \& Francis Group.

4. Demerouti E, Bakker AB, Butlers AJ (2004) The loss spiral of work pressure, work-home interference and exhaustion: reciprocal relations in a threewave study. Journal of Vocational Behavior 64: 131-149.

5. Cordes CL, Dougherty TW (1993) A review and an integration of research on job burnout. Academy of Management Review18: 621-656.

6. Pines A, Aronson E, Kafry D (1981) Burn Out: From Tedium to Paersonal Growth: Free Press.

7. Duncan D (2016) Zeiterfahrung von Burnout-PatientInnen. Eine qualitative Erhebung zum subjektiven Zeitempfinden. In: Bodytime. Leib und Zeit bei Burnout und in anderen Grenzerfahrungen. Published by Esterbauer R, Paletta A, Schmidt P, Duncan D (2016) Freiburg / München: Verlag Karl Alber.

8. Litzcke S, Schuh H (2010) Stress, Mobbing, Burnout am Arbeitsplatz. Heidelberg: Springer.

9. Duncan D (2019) Die Körpererfahrung von Burnout-Patientinnen und -Patienten. In: Der Leib und seine Zeit. Temporale Prozesse des Körpers und deren Dysregulationen im Burnout und bei anderen Leiberfahrungen. Published by Esterbauer R, Paletta, Meer J (2019) Freiburg / München: Verlag Karl Alber.

10. Schilder P (1935) The Image and Appearance of the Human Body: Studies in the Constructive Energies of the Psyche. London: K. Paul, Trench, Trubner\& Company Limited.

11. Müller E (2003) Ausgebrannt - Wege aus der Burnout-Krise. Freiburg im Breisgau: Verlag Herder.

12. Bielefeld J (1991) Körpererfahrung - Grundlagen menschlichen Bewegungsverhaltens. Göttingen: Verlag für Psychologie. 
Citation: Duncan D (2020) The Burnout Syndrome-A Synopsis of Time and Body Experience of Patients Suffering from Burnout. Int J Phys Ther Rehab 6: 161. doi: https://doi.org/10.15344/2455-7498/2020/161

Page 9 of 9

13. Duncan D (2017) Body Experience of Burnout-patients. Int J PhysTher Rehab 3: 125.

14. Kiener F (1973) Untersuchungen zum Körperbild (Body Image), 1.Teil Zeitschrift für klinische Psychologie und Psychtherapie 21: 336.

15. Bruch $\mathrm{H}$ (1962) Perceptual and conceptual disturbances in anorexia nervosa Psychosom Med 24: 187-194.

16. Günter $M$ (2009) Körperbildforschung bei Kindern mit Hilfe des Körperbildmaltests für Kinder (KMBT-K). In: Joraschky P, Loew T, Röhricht F (Ed.) Körpererleben und Körperbild. Ein Handbuch zur Diagnostik. Stuttgart: Schattauer

17. Blasche G (2012) Burnout - Therapie und Kur. Ärzte Exklusiv 16: 20-21.

18. Wiseman $T$ (2007) Toward a holistic conceptualization of empathy for nursing practice. ANS Adv Nurs Sci 30: E61-E72.

19. Schöneck N (2009) Zeiterleben und Zeithandeln Erwerbstätiger. Eine methodenintegrative Studie. Wiesbaden: GWV. 